\title{
Recent studies on germanium-nanomaterials for LIBs anodes
}

\author{
Vladko Panayotov ${ }^{1}$, Marinela Panayotova ${ }^{2,}$, and Serhii Chukharev $^{3}$ \\ ${ }^{1}$ Bulgarian Academy of Sciences, 1 "15 Noemvri” Str., Sofia, 1040, Bulgaria \\ ${ }^{2}$ University of Mining and Geology, 1 "Boyan Kamenov" Str., Sofia, 1700, Bulgaria \\ ${ }^{3}$ National University of Water and Environmental Engineering, Department of Mining Development and Mining, 11 Soborna Str., \\ Rivne, Ukraine
}

\begin{abstract}
The inherently law capacity of the classically used carbon-based anode is one of the major drawbacks hindering the wide application of lithium ion batteries (LIBs) in electric vehicles. Carbon replacement with materials possessing high theoretical capacity, such as germanium $(\mathrm{Ge})$ represents one of the approaches used for ensuring wider LIBs' implementation. The main disadvantage of the Ge use is its huge volume change during the lithiation / delithiation, causing Ge-based electrodes pulverization, deterioration of the electrochemical properties and resulting in electrodes relatively short life. Usage of Ge based nanomaterials is regarded as powerful tool for overcoming the mentioned drawbacks. This paper reviews and discusses the very recent progress in the preparation and studying the Ge nanoparticles (NPs), Ge nanoalloys and Ge-based nanocomposites as attempts for preparation of advanced anodes for LIBs.
\end{abstract}

\section{Introduction}

The lithium-ion batteries are widely used and their application in portable electronics and electric vehicles or hybrid electric vehicles is expected to be increased. LIBs are rechargeable batteries possessing high energy density, low self-discharge and no memory effect. Every LIB (more correctly a battery pack) consists of gathered together electrically connected electrochemical cells and electronics for control and protection. The cell (that is the primary electrochemical unit) contains electrodes, separator, and electrolyte. In the most commercial cells the negative electrode (anode) is made of graphite.

The positive electrode is a lithium-based material. It can be a layered oxide (for example lithium cobalt oxide), a polyanion (like lithium iron phosphate), or a spinel (for instance lithium manganese oxide). The electrolyte usually represents a mixture of organic carbonates, typically ethylene carbonate (EC), diethyl carbonate (DEC), ethyl methyl carbonate (EMC), dimethyl carbonate (DMC), containing lithium complexes, such as lithium hexafluorophosphate $\left(\mathrm{LiPF}_{6}\right)$, lithium perchlorate $\left(\mathrm{LiClO}_{4}\right)$, lithium tetrafluoroborate $\left(\mathrm{LiBF}_{4}\right)$, lithium hexafluoroarsenate monohydrate $\left(\mathrm{LiAsF}_{6}\right)$, and lithium triflate $\left(\mathrm{LiCF}_{3} \mathrm{SO}_{3}\right)$.

Anode and cathode allow lithium ions $\left(\mathrm{Li}^{+}\right)$to move in and out of their framework, the $\mathrm{Li}^{+}$insertion process (lithiation) is called intercalation and the $\mathrm{Li}^{+}$extraction (delithiation) one - deintercalation. During the discharge an oxidation reaction proceeds at the anode and positively charged $\mathrm{Li}^{+}$and negatively charged electrons are formed. The $\mathrm{Li}^{+}$move through the electrolyte to the cathode where they are inserted in the cathode material (often forming a lithium compound) with the aid of electrons that are transported from anode through an external circuit to the cathode. When the cell is being charged, the reverse reaction occurs - the $\mathrm{Li}^{+}$and electrons move back into the negative electrode.

The capacity decrease in LIBs is most often due to the loss of lithium to the solid-electrolyte interphase (SEI) that forms at the negative electrode. Initially, during charging at temperature below $25^{\circ} \mathrm{C}$ metallic lithium is produced spontaneously on the electrode surface. Further the lithium reacts with electrolyte to form $\mathrm{Li}_{2} \mathrm{O}, \mathrm{LiF}, \mathrm{Li}_{2} \mathrm{CO}_{3}$, and polyolefins. This is due to the fact that the electrolytes typically used in LIBs are not stable at the electrode operating potential during charging and they may decompose. At the beginning, SEI formation increases the electrode resistance to solvent decomposition but the increase in the SEI thickness with time leads to a gradual decrease of the LIB's capacity.

The commercial graphite exhibits a relatively low theoretical capacity of $372 \mathrm{mAh} / \mathrm{g}$ (electrode capacities are compared by using three measures: specific energy or gravimetric capacity (capacity per unit of mass), volumetric capacity (capacity per unit volume), and areal capacity (area-normalized specific capacity)). This fact leads to an intensive search for other materials. Materials forming alloys with $\mathrm{Li}$, such as $\mathrm{Si}, \mathrm{Ge}, \mathrm{Sn}$ are actively researched as alternatives to carbon-based anodes for rechargeable LIBs due to their higher theoretical capacities in comparison to commercial graphite. For example, Ge possesses theoretical specific capacity of $1600 \mathrm{mAh} / \mathrm{g}$ (at $4.4 \mathrm{Li}^{+}$per $\mathrm{Ge}$ atom), an electronic conductivity $10^{4}$ times higher than silicon, and high $\mathrm{Li}^{+}$ diffusivity (more than 400 times higher than that in silicon at room temperature) [1].

* Corresponding author: marichim@mgu.bg 
The unsatisfying cycle life (due to the volume expansion / contraction during the lithiation / delithiation reaction, causing the formation of cracks, pulverization of the electrodes, destroying the conductive network of the electrode, thus deteriorating the storage capacity of lithium and worsening the cycle performance) appeared as one of the most challenging problems of the recently developed anode materials. Ge particles aggregation during the $\mathrm{Li}^{+}$insertion / extraction leads to an increase in the internal resistance and in $\mathrm{Li}^{+}$diffusion path resulting in inability of the internal $\mathrm{Ge}$ particles to participate in chemical reactions. The final result is capacity loss and more generally - poor electrochemical performance.

The investigations trying to solve the abovementioned problems are going to the following directions: (a) alloying with the Li-active / inactive materials, (b) preparing nano-structured electrodes, and (c) surface modification by introducing conducting and / or nonconducting buffer components [2].

Application of nanostructured materials is considered a promising approach for bettering the electrochemical properties of electrodes. Nanostructured electrodes posses a very large specific surface area that can increase the contact area between the electrodes and the electrolyte. This big contact area is able to accelerate the exchange of ions and electrons at the electrode / electrolyte interface. Furthermore, owing to their very short internal diffusion paths, the nanoscale materials possess much higher ionic or electronic conductivities compared to their bulk counterparts. In addition, they can also resist to bigger mechanical deformation during charge / discharge cycling. Since Ge possesses high theoretical capacity, good electrical conductivity and fast $\mathrm{Li}^{+}$diffusivity, Ge-based nanomaterials have recently attracted considerable attention as LIB electrode materials.

Recently, different nanoscale Ge-based anodes with a variety of morphologies have been developed to raise the electrochemical performances of these anodes and the results are presented in the worldwide literature.

The most comprehensive overview of anodes for LIBs is provided by $\mathrm{Hu}$ and co-authors [3]. The paper covers studies carried out till the first quarter of 2016. The paper has extensively reviewed the preparation and the entire characterization of nanoparticles (NPs), nanowires (NWs), and nanotubes (NTs) made of single $\mathrm{Ge}, \mathrm{Ge}$ alloys with metals (such as $\mathrm{Cu}, \mathrm{Sn}$ ), with semiconductors (such $\mathrm{Si}, \mathrm{Se}$ ), and germanium chalcogens alloys such as $\mathrm{GeS}$.

Preparation of electrodes based on Ge/carbon nanotubes (CNTs), Ge/graphene, Ge-reduced graphene oxide-CNTs (Ge-RGO-CNTs), Ge-reduced graphene oxide nanofibres (Ge@RGO NFs) aimed at achieving a longer cycling life of the LIBs and their characterization is also presented by the same paper.

A special attention is paid to the preparation and characterization of core-shell structural electrodes because of their high conductivity, excellent stability and the ability to prevent the significant volume changes in the Ge electrode during the charge/discharge process. LIB anodes based on Ge@C core-shell; Ge@ $\mathrm{Cu}$ coreshell; Ge@C/graphene, Ge@C/RGO,Cu@Ge core-shell
$\mathrm{NW}$; and 3D $\mathrm{TiO}_{2} @ \mathrm{Ge}$ core-shell nanorod arrays on carbon textiles are briefly discussed.

Attention is drawn also to LIB anodes made of Ge based nanomaterials (NWs, NPs, and nanorods) that are ternary alloys and their composites (such as $\mathrm{Cu}_{3} \mathrm{Ge} / \mathrm{Ge}$ NWs, $\mathrm{Cu}_{3} \mathrm{Ge} / \mathrm{Ge} @$ graphene aerogel), as well as double oxides and their composites (such as $\mathrm{CuGeO}_{3}$, $\mathrm{Cu}_{3} \mathrm{Ge} / \mathrm{GeO}_{\mathrm{x}} / \mathrm{CuGeO}_{3} \mathrm{NWs}, \mathrm{CuGeO}_{3} \mathrm{NWs} /$ graphene composites, $\mathrm{CuGeO}_{3} @ \mathrm{RGO}$ composites, $\mathrm{Ca}_{2} \mathrm{Ge}_{7} \mathrm{O}_{16}$ NWs on carbon textiles, $\mathrm{Ca}_{2} \mathrm{Ge}_{7} \mathrm{O}_{16} \mathrm{NW} /$ graphene sheet nanocomposite, $\mathrm{Zn}_{2} \mathrm{GeO}_{4} \mathrm{NWs}$ and nanorors, $\mathrm{Zn}_{2} \mathrm{GeO}_{4}$ GO nanocomposite, $\mathrm{Cd}_{2} \mathrm{GeO}_{4} \mathrm{NWs}, \mathrm{Cd}_{2} \mathrm{GeO}_{4} \mathrm{NW} /$ $\mathrm{CNT}$ and the $\mathrm{Cd}_{2} \mathrm{GeO}_{4} \mathrm{NW} / \mathrm{GO} / \mathrm{CNT}$ nanocomposite films, $\mathrm{PbGeO}_{3} \mathrm{NWs}, \mathrm{SrGe}_{4} \mathrm{O}_{9}$ and $\mathrm{BaGe}_{4} \mathrm{O}_{9} \mathrm{NWs}$ ).

The results from testing the all above-mentioned materials as anodes in cells for LIBs are also presented.

Additionally, a brief discussion is given on the performance of LIBs electrodes made of germanium oxide $\left(\mathrm{GeO}_{2}\right)$ NPs, $\mathrm{GeO}_{2} \mathrm{NPs} / \mathrm{RGO}$ composite, and $\mathrm{GeO}_{2}-\mathrm{C}$ fibre composite.

Influence of the LIB's electrolyte type, the discharge current density, the working temperature, the cycling rate $^{1}$, the shape and morphology of the Ge-based materials has been presented when it was discussed in the original papers.

For all presented electrodes data are provided on the specific capacity $(\mathrm{mAh} / \mathrm{g})$ - initial and after cycling, current density $(\mathrm{mA} / \mathrm{g})$ and the number of chargedischarge cycles. However, for comparative purposes, the data presented have to be used cautiously, going to the original papers to check the exact cycling rate and the number of cycles related to the reported specific capacities and current densities.

An other review paper is devoted to the advances in studies on the synthesis, optical properties and applications of germanium nanocrystals, including their use as anodes for LIBs [4]. The paper covers studies carried out in the period 2010-2015 and only two of the papers reviewed in [3] are referred to also in [4]. The author pays special attention to the Ge nanocrystals (NCs) use in anodes for LIBs. The Ge NCs/RGO composite and a composite of Ge NCs encapsulated within carbon nanofibers $((\mathrm{Ge}) 0 \mathrm{D} @(\mathrm{CNF}) 1 \mathrm{D})$ are presented, including means for those composites preparation, their characterization and results from their testing as anodes for LIBs (specific capacity $(\mathrm{mAh} / \mathrm{g})-$ initial and after cycling at different rate, and the number of charge-discharge cycles).

Figure 1 presents schematically the major Ge-based nanomaterials studied until 2016 as potential anode (active) materials for LIBs.

Having in mind the importance of developing highperformance LIBs and the exponentially growing studies in the area, we consider that it would be useful for the

\footnotetext{
${ }^{1}$ A C-rate is a standard unit of the rate at which a battery is discharged with respect to its maximum capacity. A $1 \mathrm{C}$ rate denotes that the discharge current will discharge the whole battery in 1 hour. As an example, for a battery with a capacity of $100 \mathrm{Ah}, 1 \mathrm{C}$ is equal to a discharge current of $100 \mathrm{~A}$, a $5 \mathrm{C}$ rate for this battery would be $500 \mathrm{~A}$. (http://web.mit.edu/evt/summary_battery_specifications.pdf)
} 
reader to be supplied with up-to-dated information on the subject.

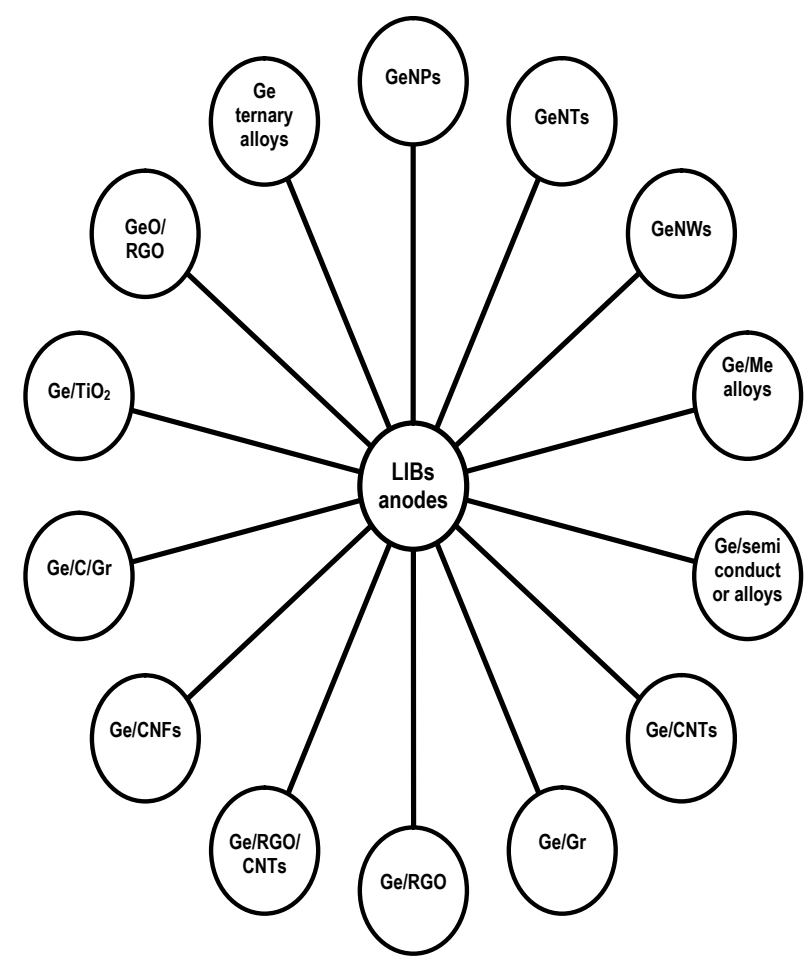

Fig. 1. Schematic representation of the major Ge-based nanomaterials studied until 2016 as potential anode (active) materials for LIBs

In this mini-review article, we overview the further development in the use of Ge-based nanomaterials and nanocomposites for LIBs' anodes by covering the studies in the recent three years.

\section{Recent approaches for preparing germanium based nanomaterials for high-performance anodes for LIBs}

The studies aimed at improving the performance of $\mathrm{Ge}$ containing LIBs anodes in the recent 3-4 years have continued in the following directions: nano-structured germanium, germanium oxide based materials, germanium alloys based nanomaterials and preparation of electrodes based on Ge and carbon (or its derivatives).

\subsection{Nano-structured germanium}

A new direction in the synthesis Ge-based nanomaterials for LIBs is proposed that relays on pulsed laser-assisted electrodeposition from ionic liquid at room temperature [5]. The utilized ionic liquid was 1-ethyl-3-methylimidazolium bis (trifluoromethylsulfonyl) imide $([\mathrm{EMIm}] \mathrm{Tf} 2 \mathrm{~N})$ that did not require supporting electrolytes as is the case with organic solvents. The laser irradiation allowed for controlling the size, shape, and distribution of nanoparticles since it ensured clustering and vertical growth of $\mathrm{Ga}$ nanospheres and further development of Ge nanowires (non-branched and branched). The pulsed laser irradiation facilitated the direct electrodeposition of Ge nanowires on a copper (Cu) foil.

The characteristics of the produced material were studied utilizing home-made cells. The Ge NW electrode was used to prepare coin-type half cells (2025R size) by applying Li metal as the counter electrode. The separator was a microporous polyethylene (PE) and the electrolyte was $1 \mathrm{~mol} / \mathrm{L} \mathrm{LiPF}_{6}$ in EC-DEC mixture. The prepared Ge nanowire anode exhibited an initial discharge capacity of $1646 \mathrm{mAh} / \mathrm{g}$ and initial charge capacity of $1278 \mathrm{mAh} / \mathrm{g}$. The large initial discharge capacity and irreversible capacity loss measured were assigned to the irreversible formation of SEI. However, the capacity reversibility was much better in the next cycles and the capacity of $884 \mathrm{mAh} / \mathrm{g}$ was retained after 50 cycles at $0.2 \mathrm{C}$, while the coulombic efficiency (CE) was higher than $96 \%$. The capacity decay was less pronounced compared to that observed for Ge nanoparticle film prepared by non laser-assisted electrodeposition.

The studied Ge nanowire electrode showed reversible capacities of 1230,1160,1070, 960, and $730 \mathrm{mAh} / \mathrm{g}$ at $0.1 \mathrm{C}, 0.2 \mathrm{C}, 0.5 \mathrm{C}, 1 \mathrm{C}$, and $2 \mathrm{C}$, correspondingly. In addition, the capacity returned to $1100 \mathrm{mAh} / \mathrm{g}$ when the rate was decreased to $0.1 \mathrm{C}$. These findings show that the properties of pure Ge anodes can be improved by pulsed laser assisted ionic liquid electrodeposition. The improved properties of thus prepared electrode were assigned to the laser-assisted transformation of the amorphous $\mathrm{Ge}$ deposits from films in the absence of laser irradiation to polycrystalline structures (nanowires and branched nanowires) under laser irradiation. This structure supplies channels facilitating the transport of $\mathrm{Li}^{+}$. The result is higher diffusion rate of $\mathrm{Li}^{+}$. The polycrystallinity of the nanostructures also averts pulverization of the electrode materials during LIBs' cycling by facilitating volumetric expansion throughout the entire nanostructure.

Preparation of porous structures is considered an efficient way for mitigating the negative effect of the LIBs' volume expansion and contraction during lithiation and delithiation. In this line, a 3D ordered macroporous (3DOM) nickel $(\mathrm{Ni})$ framework (Ge/3DOM-Ni) was prepared by using drop-coating technique to attach $\mathrm{Ge}$ nanoparticles to the $\mathrm{Ni}$ framework [6]. Germanium nanoparticles were produced by reduction of germanate ions with $\mathrm{NaBH}_{4}$, the former were prepared through reaction of $\mathrm{GeO}_{2}$ with $\mathrm{NaOH}$. Thus prepared Ge nanoparticles were dispersed in ethanol by ultrasonication. The obtained suspension was drop-coated onto the heated 3DOM-Ni framework. The self-supporting porous Ge/3DOM-Ni electrodes were produced by annealing the 3DOM-Ni framework, bearing the Ge nanoparticles, at $500{ }^{\circ} \mathrm{C}$ for $2 \mathrm{~h}$ in $\mathrm{Ar}$ atmosphere.

To study the properties of thus prepared anodes a coin-type half cells (2025R size) were assembled. Microporous PE was used as the separator, Li metal as counter and reference electrode, and $1 \mathrm{M} \mathrm{LiPF} 6$ in EC DEC $(1: 1$ vol.\%) as the electrolyte. The dischargecharge study was carried out at a current density of $0.2 \mathrm{C}$ (1C is approximately $1600 \mathrm{~mA} / \mathrm{g}$ ) within the potential range of $0.01-2 \mathrm{~V}$ (vs. $\left.\mathrm{Li}^{+} / \mathrm{Li}\right)$. Initially a low $\mathrm{CE}$ of 
$53.3 \%$ was recorded, corresponding to the initial discharge and charge capacities of approximately 1869 and $996 \mathrm{mAh} / \mathrm{g}$. This effect is assigned to the SEI layer formation. The discharge and charge capacities for the second cycle were 1053 and $1052 \mathrm{mAh} / \mathrm{g}$, correspondingly, ensuring the $\mathrm{CE}$ of approximately $100 \%$. No definite variation was observed in the specific charge capacities of the Ge/3DOM-Ni electrodes in the initial 10 cycles, pointing at good structural stability. After 100 cycles a specific charge capacity of 610 $\mathrm{mAh} / \mathrm{g}$ was observed while the CE remained c.a. $100 \%$.

The rate performance of the Ge/3DOM-Ni electrode was studied at rates of $0.1 \mathrm{C}, 0.2 \mathrm{C}, 0.5 \mathrm{C}, 1 \mathrm{C}, 2 \mathrm{C}, 5 \mathrm{C}$, and 10C. The obtained respective reversible capacities of the Ge/3DOM-Ni electrodes were approximately 1337 , $1042.5,930,817.5,685,460$, and $270 \mathrm{mAh} / \mathrm{g}$. The good performance of the Ge/3DOM-Ni electrode is mainly attributed to the 3DOM-Ni framework, since the easily accessible macroporous channels ensure efficient transport pathways for electrolyte and $\mathrm{Li}^{+}$and highly conductive framework for electron transport. The high porosity of the prepared electrode (confirmed by SEM observations) helped to avoid the negative effect of the volume enlargement of the Ge nanoparticles at cycling. The work showed that porous Ni frameworks are good supports and current collectors for Ge-based LIBs anodes. The use of polymer binders and conductive substances is avoided, thus the specific capacity is increased.

Recently a study is reported on the effect of mass loading on the areal capacity, capacity retention, and rate performance in high-capacity Ge electrodes for LIBs [7]. The results are of interest, since the application of electrodes with an areal capacity over $3 \mathrm{mAh} / \mathrm{cm}^{2}$ meets different obstacles, such as electrode delamination from the current collector, increased resistance - electronic and ionic, substandard electrolyte penetration, and underutilization of the electrode at high current densities. To overcome the problems, a porous Ge was prepared by reducing $\mathrm{GeO}_{2}$ under hydrogen atmosphere at $450{ }^{\circ} \mathrm{C}$. Further a the slurry was prepared by mixing $70 \mathrm{wt} . \%$ of the produced active material with the binder (20 wt.\% poly (acylic) acid) and the conductive agent (10 wt.\% acetylene black). The electrodes were elaborated by tape casting of the produced slurry.

To study the electrochemical behaviour of the prepared electrodes CR2016 coins cells were fabricated. Metal $\mathrm{Li}$ was used as the counter electrode for the half cells and commercial $\mathrm{LiCoO}_{2}$ electrodes were applied in studies on the full cell cyclic performance. The electrolyte applied consisted of $1 \mathrm{M} \mathrm{LiPF} 6$ in mixture of ED, DEC and DMC (1:1:1 by volume).

The electrochemical behaviour of the Ge electrode was studied using galvanostatic charge/discharge process in the range of 0.02 and $1.2 \mathrm{~V}$ vs $\mathrm{Li} / \mathrm{Li}^{+}$. At a current density of $1000 \mathrm{~mA} / \mathrm{g}, 340$ stable cycles were achieved and the final specific capacity was approximately 1300 $\mathrm{mAh} / \mathrm{g}$ for the mass loading of c.a. $1 \mathrm{mg} / \mathrm{cm}^{2}$. The slight capacity drop in the initial cycles was assigned to the formation of SEI, as well as to some loss of electrical contact due to the rearrangement of active materials. The increase in the specific capacity at further cycling is assigned to the electrode activation by the deeper lithiation into the active materials. The first cycle $\mathrm{CE}$ was $60 \%$, it increased to $92 \%$ for the 2 nd cycle, and reached approximately $99 \%$ for the 10 th cycle.

The electrode cyclic performance was studied (up to 1800 cycles) at the high current density of $5 \mathrm{C}$ (i.e. $8 \mathrm{~A} / \mathrm{g}$, since $1 \mathrm{C}=1600 \mathrm{~mA} / \mathrm{g}$ ) and at the low loading of 0.56 $\mathrm{mg} / \mathrm{cm}^{2}$. A CE over $99 \%$ was achieved starting from the 3rd cycle. This long term cycleability at the high rate was explained by the porous morphology of the Ge electrode that was able to sustain the lithiation induced stress without undergoing pulverization. In addition, the electrode with such morphology provided better electrolyte accessibility and simultaneously ensured shorter $\mathrm{Li}^{+}$diffusion lengths.

To evaluate the practical behaviour of the electrode, the electrochemical characteristics of a full cell consisting of Ge anode and lithium cobalt oxide cathode was studied. At a current density of $1 \mathrm{~mA} / \mathrm{cm}^{2}$ the areal capacity at the end of 180 cycles was $0.68 \mathrm{mAh} / \mathrm{cm}^{2}$ at CE of $99.6 \%$.

Transmission electron microscopy (TEM) and selected area electron diffraction were used to study the electrode morphology before and after cycling and the phase transformation. The results indicated that the electrode stability resulted from the ability of the individual grains to keep the electrical contacts between them, even at big changes in the volume due to the lithiation.

Macroporous (MP) $\mathrm{Ge} @ \mathrm{TiO}_{2}$ composite, consisting of nanoscale $\mathrm{Ge}$ network skeleton wrapped with $\mathrm{TiO}_{2}$ particles was prepared by dealloying of $\mathrm{Ge}_{4.5} \mathrm{Ti}_{0.5} \mathrm{Al}_{95}$ alloy via its immersion in $0.01 \mathrm{~mol} / \mathrm{L} \mathrm{NaOH}$ solutions at $25{ }^{\circ} \mathrm{C}$ for $4 \mathrm{~h}$ [8]. During the selective dissolution of $\mathrm{Al}$, $\mathrm{Ge}$ atoms were brought together and formed three dimensional (3D) network nanostructure with high porosity. Meanwhile Ti atoms were oxidized and further (by a spontaneous aggregation) formed $\mathrm{TiO}_{2}$ particles layer that covered the porous Ge surface.

In order to study the lithium storage performances of the prepared $\mathrm{Ge} @ \mathrm{TiO}_{2}$ material, CR2032 coin-type cells were fabricated where $\mathrm{Ge} @ \mathrm{TiO}_{2}$-based material served as the anode active substance. Anodes with pure Ge as active material were also prepared for comparison. The other materials included in the slurry used to prepare anodes, besides the active materials, were Super P, and sodium alginate. $\mathrm{Cu}$ foil was used as current collector. The counter electrode was a lithium foil, and the separator - a microporous membrane. The electrolyte was $1 \mathrm{~mol} / \mathrm{L} \mathrm{LiPF}_{6}$ dissolved in the mixture of EMC, DMC and EC (1:1:1 - a volume ratio) with an addition of $3 \mathrm{v} . \%$ vinylene carbonate (VC) that acts as film forming additive.

Studies on the cycling performances and CEs of $\mathrm{Ge} @ \mathrm{TiO}_{2}$ anode and pure Ge anode were carried out at current density of $400 \mathrm{~mA} / \mathrm{g}$. The Ge@ $\mathrm{TiO}_{2}$ electrode provided a reversible capacity of $963 \mathrm{mAh} / \mathrm{g}$ after 100 cycles while the capacity of pure Ge was $418 \mathrm{mAh} / \mathrm{g}$, thus suggesting the more stable lithium storage performances of the $\mathrm{Ge} @ \mathrm{TiO}_{2}$ material.

The cycling performances of MP Ge@ $\mathrm{TiO}_{2}$ and pure Ge anodes at current density of $3200 \mathrm{~mA} / \mathrm{g}$ were also studied. $\mathrm{Ge} @ \mathrm{TiO}_{2}$ maintained reversible capacity of 
$716.7 \mathrm{mAh} / \mathrm{g}$ after 300 cycles, while the capacity of pure Ge electrode at the 300th cycle was $126.4 \mathrm{mAh} / \mathrm{g}$. TEM images showed that the structure of pure Ge underwent serious fracture and collapse after cycling while the $\mathrm{Ge} / \mathrm{TiO}_{2}$ material preserved its original porous network architecture.

The rate performances of MP Ge@ $@ \mathrm{TiO}_{2}$ and pure Ge electrodes were studied, as well. The $\mathrm{Ge} @ \mathrm{TiO}_{2}$ electrode exhibited specific discharge capacities of 1182.2, 1040.4, $955.3,820.0$, and $774.8 \mathrm{mAh} / \mathrm{g}$ at the current densities of $160,400,800,1600$ and $3200 \mathrm{~mA} / \mathrm{g}$, correspondingly. The pure Ge showed lower capacity at all current densities and a discharge capacity of only $134.6 \mathrm{mAh} / \mathrm{g}$ at $3200 \mathrm{~mA} / \mathrm{g}$. When the current density was back to 160 $\mathrm{mA} / \mathrm{g}$ (after it was $3200 \mathrm{~mA} / \mathrm{g}$ ) the specific capacity for $\mathrm{Ge} @ \mathrm{TiO}_{2}$ returned to $1036.5 \mathrm{mAh} / \mathrm{g}$ indicating very good rate performance.

The excellent characteristics of the prepared material were explained by its structure. The 3D macroporous network with its channels accelerates the movement of electrons and ions during lithiation/delithiation process. The robust $\mathrm{TiO}_{2}$ layer ensures mechanical strength and prevents the direct contact between Ge and electrolytes, thus hindering the continuous increase of SEI which causes the capacity decrease.

\subsection{Germanium oxide based nanomaterials}

Due to its high theoretical capacity of $2152 \mathrm{mAh} / \mathrm{g}$, in the case that it reversibly stores $8.4 \mathrm{Li}^{+}, \mathrm{GeO}_{2}$ is considered as an encouraging anode material for LIBs [9]. In addition, $\mathrm{GeO}_{2}$ is cheaper than pure Ge. However, its fast implementation in LIBs is hindered by the $\mathrm{GeO}_{2}$ poor electrical conductivity and the very big volume changes during the charge/discharge process, resulting in the degradation (pulverization) of the electrode material, unstable SEI and as a result poor performance. In an attempt to obtain novel $\mathrm{GeO}_{2}$-based anode materials with enhanced performance, preparation of porous $\mathrm{GeO}_{2}$ nanoparticles through thermal decomposition of (Hbipy $)_{2}\left[\mathrm{Ge}\left(\mathrm{C}_{2} \mathrm{O}_{4}\right)_{3}\right] \cdot 2 \mathrm{H}_{2} \mathrm{O}$ in air atmosphere has been proposed [9]. The idea was to use the ability of porous structures to relax the mechanical strain resulting from the volume expansion during cyclic process, as well as their large surface area facilitating electrode-electrolyte interface, and thin walls ensuring fast diffusion of $\mathrm{Li}^{+}$.

The prepared porous $\mathrm{GeO}_{2}$ nanoparticles possessed an average size of $200 \mathrm{~nm}$, pores of $4 \mathrm{~nm}$, BET surface area of $74.0 \mathrm{~m}^{2} / \mathrm{g}$ and total pore volume of $0.208 \mathrm{~cm}^{3} / \mathrm{g}$.

When used as LIB's anode the materials exhibited a discharge capacity of $2578.8 \mathrm{mAh} / \mathrm{g}$ at current density of $100 \mathrm{~mA} / \mathrm{g}$. Even at current density of $2 \mathrm{~A} / \mathrm{g}$, the reversible specific capacity was $184.2 \mathrm{mAh} / \mathrm{g}$. After the high-rate measurements, the specific reversible capacity was $727 \mathrm{mAh} / \mathrm{g}$ when the current density was set back to $100 \mathrm{~mA} / \mathrm{g}$. This finding points at good electrochemical reversibility and structure stability.

A comparison of commercial $\mathrm{GeO}_{2}$ and the synthesized porous $\mathrm{GeO}_{2}$ nanoparticles pointed at the superiority of the latter. After 100 cycles at $100 \mathrm{~mA} / \mathrm{g}$, the porous $\mathrm{GeO}_{2}$ possessed a reversible capacity of 581.9
$\mathrm{mAh} / \mathrm{g}$ for $\mathrm{Li}^{+}$storage, while that of the commercial $\mathrm{GeO}_{2}$ was $256.5 \mathrm{mAh} / \mathrm{g}$. The good performance of the prepared material is assigned to the synergism of nanoscale, porous structure and low crystalline structures formed during the synthesis.

One-pot environmentally friendly synthesis of amorphous $\mathrm{Ge}$ oxide-carbon $\left(\mathrm{GeO}_{\mathrm{x}}-\mathrm{C}\right)$ hollow composite has been proposed by using citric acid (CA) as reductant of the germanium ions obtained by dissolving $\mathrm{GeO}_{2}$ in $\mathrm{NH}_{4} \mathrm{OH}$ [10]. The amount of the added reductant influenced the thickness of the resulting hollow structure, but the hollows' size of the $\mathrm{GeO}_{\mathrm{x}}$ materials was not changed. Under the optimum ratio of $\mathrm{CA}$ to $\mathrm{GeO}_{2}$ 13-16 nm shells were formed and this material showed the best electrochemical performance.

The LiB anode prepared using this material exhibited a capacity of $930 \mathrm{mAh} / \mathrm{g}$ after 100 cycles at rate of $0.3 \mathrm{C}$, while the CE was $99.9 \%$.

The cycling stability of the $\mathrm{GeO}_{\mathrm{x}}-\mathrm{C}$ hollow composite was studied by gradually applying C-rate from $0.1 \mathrm{C}$ to $10 \mathrm{C}$. At that, the specific capacity of the sample slowly decreased from 956 to $612 \mathrm{mAh} / \mathrm{g}$. Nevertheless, when $0.5 \mathrm{C}$ was applied after $10 \mathrm{C}$, the reversible capacity come back to $935 \mathrm{mAh} / \mathrm{g}$ showing a very good performance. The repetitive fast cycles charge/discharge' carried out at rate of $2 \mathrm{C}$ showed that after 400 cycles the reversible capacity was $757 \mathrm{mAh} / \mathrm{g}$, (approximately 90\% retention compared to the second cycle) pointing at good cycling stability.

It has been found that during the lithiation/ delithiation process the thickness of the $\mathrm{GeO}_{\mathrm{x}}-\mathrm{C}$ hollow composite electrode changed by approximately $12 \%$, while the thickness of an electrode prepared from commercial $\mathrm{GeO}_{2}$ changed by up to $150 \%$. The HRTEM analysis of the $\mathrm{GeO}_{\mathrm{x}}-\mathrm{C}$ hollow composite showed well preserved hollow structure and uniform distribution of $\mathrm{Ge}$ and $\mathrm{O}$ atoms even after 400 cycles.

The enhanced electrochemical performance of the $\mathrm{GeO}_{\mathrm{x}}-\mathrm{C}$ hollow composite was assigned to the synergistic effect of the hollow structure with optimized thickness of the shells, amorphous nature, and the presence of conductive carbon. The composite shell layers supplied a surface for formation of stable SEI layer by avoiding the direct contact between the electrolyte and the anode. Availability of an internal void space ensured free expansion of the anode material without increasing the volume of the entire electrode. All these features allowed for an effective accommodation of volume change and facilitated transport of electrons during charge/discharge process.

\subsection{Germanium alloys-based nanomaterials}

Germanium alloying represents one of the ways for mitigating/avoiding the structural pulverization and loss of electrical conduction paths between the active materials and current collector in LIBs' anodes. In line with these efforts free standing non-carbon electrodes were prepared by mixing $\mathrm{Ge}$ and $\mathrm{Cu}$ nanowires [11]. The electrodes were tested as anodes for LIBs. Half-cells (of CR2032 type) were prepared using as working electrode 
the produced free standing NW fabric, Li metal foil was the counter electrode. The electrolyte was $1 \mathrm{M} \mathrm{LiPF}_{6}$ in 3:7 (v/v) fluoroethylene carbonate/dimethyl carbonate (FEC/DMC) and it was loaded on a microporous PE separator. The material prepared under optimum conditions exhibited initial charge and discharge capacities of $1348 \mathrm{mAh} / \mathrm{g}$ and $1107 \mathrm{mAh} / \mathrm{g}$ corresponding to the $\mathrm{CE}$ of $82.1 \%$. Its capacity retention was $80.3 \%$ after 50 cycles.

High-resolution SEM and TEM images of the electrodes before and after 100 cycles showed that before cycling Ge nanowires waved with each other into the fabric structure. The X-ray spectroscopy (EDS) of the contact point revealed that the atomic ratio of $\mathrm{Cu}$ to Ge was 3:2, which proved the formation of copper germanide. After cycling, the nanowire composites were coated by a uniform SEI layer.

The free standing NW fabric electrodes possess the following advantages for application in LIBs: (i) The elaborated electrode structure needs neither a metal foil current collector nor polymer binders in the production process. As a result, the whole electrode is considerably lighter than conventional electrodes made by slurry coating on metal foils; (ii) The existence of the raw material in the form of wires supplies many intersections between NWs (like 3D interconnectivity) leading to an accelerated electron transport; (iii) The space between the NWs can alleviate the volume changes during alloying and dealloying process and improve the electrolyte penetration leading to easier $\mathrm{Li}^{+}$diffusion in the electrode.

The $\mathrm{Cu}$ content and the annealing temperature were found as the two main factors determining the electrochemical performance of the free standing NW anode electrodes.

Use of core-shell array nanostructures as LIBs' anodes is able to significantly improve the electrochemical performance, especially the high-rate capability. Cobalt-germanium core-shell nanowire array anode (Co-Ge CNA) was synthesized by template-free approach applying direct deposition of a Ge layer on the surface of the preliminary synthesized Co NW arrays [12]. RF-sputtering method was used.

To study the performance of the produced material as anode for LIBs, 2025 coin-type half cells were assembled with a metallic lithium foil as the counter electrode, $1 \mathrm{M}$ solution of $\mathrm{LiPF}_{6}$ in EC / DMC (1:1 by volume) as electrolyte and polypropylene micro-porous film as a separator.

At a current density of $320 \mathrm{~mA} / \mathrm{g}$ the initial discharge and charge capacities of Co-Ge CNA were 1994.8 and $1441.4 \mathrm{mAh} / \mathrm{g}$ correspondingly, resulting in an initial Coulombic efficiency (ICE) of $72.3 \%$. The irreversible capacity loss in the first cycle is assigned to the SEI formation. In the further cycles the Co-Ge CNA anode exhibited practically constant capacity and it was 1535 $\mathrm{mAh} / \mathrm{g}$ after 100 cycles.

The rate performance of Co-Ge CNA electrodes was studied under different current rates in the range of $0.2 \mathrm{C}$ - 5C. The discharge capacities of 1493, 1482, 1467, 1357 and $1239 \mathrm{mAh} / \mathrm{g}$ were recorded at 0.2, 0.5, 1, 2 and $5 \mathrm{C}(=8000 \mathrm{~mA} / \mathrm{g})$, correspondingly. However, when again a current of $0.2 \mathrm{C}$ was applied, the Co-Ge CNA electrodes showed a capacity of $\sim 1446 \mathrm{mAh} / \mathrm{g}$ and a stable cycling performance. The good rate performance is assigned to the core-shell array nanostructures that are able to provide vigorous mechanical support, fast electron transport, and improved contact to the current collector.

\subsection{Nanocomposites of germanium and carbon- based materials}

Composites consisting of Ge NPs and carbon-based materials continue to be considered among the most promising materials for preparation of LIBs' anodes, since carbon coating on Ge particles acts as a buffer layer effectively limiting volume expansion and aggregation of Ge NPs. In comparison with amorphous carbon coating, the ordered mesoporous carbon (OMC) in addition to providing large surface area, uniform pore size and good conductivity, can be used as a matrix that contains electroactive material, exercising a confining effect and maintaining the integral structure. Combining Ge nanoparticles with the advantages of ordered mesoporous structure is considered as a plausible strategy for the synthesis of high-capacity, long-cycle life electrode materials.

A composite consisting of Ge NPs embedded in spherical ordered mesoporous carbon $(\mathrm{S}-\mathrm{OMC} / \mathrm{Ge})$ was prepared by impregnating the ammonium salt of $\mathrm{Ge}$ in the pores of $\mathrm{OMC}$, followed by high temperature pyrolysis and $\mathrm{H}_{2}$ reduction [13].

The electrochemical performance of the synthesized composite as an active anode material was tested by preparing CR 2032 coin cells. The anode contained the active material, acetylene black, and binder polyvinylidene fluoride (PVDF) at a mass ratio of 75:15:10, the current collector was $\mathrm{Cu}$ foil. A lithium plate was the counter electrode, and the electrolyte was $1.0 \mathrm{M} \mathrm{LiPF}_{6}$ in EC - DEC at ratio 1:1 vol.\%.

The cycling behaviour of $\mathrm{S}-\mathrm{OMC} / \mathrm{Ge}$ based electrodes as well as of electrodes based on pure spherical OMC (S-OMC) and pure Ge materials were studied in 160 cycles at the current density of $100 \mathrm{~mA} / \mathrm{g}$. The capacity of S-OMC sample was $643 \mathrm{mAh} / \mathrm{g}$ after 160 cycles. The capacity of Ge electrode was $173 \mathrm{mAh} / \mathrm{g}$ after 3 cycles, showing a rather poor cycling performance. The composite $\mathrm{S}-\mathrm{OMC} / \mathrm{Ge}$ sample exhibited a stable circulation in the 160 cycles, with capacity of $996 \mathrm{mAh} / \mathrm{g}$.

The rate performance of the $\mathrm{S}-\mathrm{OMC} / \mathrm{Ge}$ electrode was evaluated by applying different current densities. The measured reversible discharge capacities were 1025 , 934, 807 and $681 \mathrm{mAh} / \mathrm{g}$ at applied current densities of $100,200,500$ and $1000 \mathrm{~mA} / \mathrm{g}$, correspondingly. When the applied current density was returned to $100 \mathrm{~mA} / \mathrm{g}$, the reversible capacity was stabilized at $890 \mathrm{mAh} / \mathrm{g}$ after 60 cycles. The reversible capacities measured under the same conditions for S-OMC and pure Ge samples were much worse. The cycle stability of S-OMC/Ge electrode was studied also at high current density of $1 \mathrm{~A} / \mathrm{g}$. The 
electrode maintained a reversible capacity of $530 \mathrm{mAh} / \mathrm{g}$ after 200 cycles and the CE was stable, at $99.2 \%$.

The proposed explanation of the high capacity of S$\mathrm{OMC} / \mathrm{Ge}$ composite was by the complete structure formed by Ge particles (that possess a high theoretical capacity) even distribution in the mesoporous carbon.

It was found that the content of Ge had an effect on the performance of S-OMC/Ge composites. The low Ge content was not enough to ensure the impact of the Ge high theoretical capacity, while use excessive Ge lead to Ge agglomeration and blocking of the mesoporous carbon pores, which affected the overall performance of $\mathrm{S}-\mathrm{OMC} / \mathrm{Ge}$ composite.

The good performance of the prepared composite is assigned to the synergistic effect between the support of spherical OMC and the high capacity provided by dispersed $\mathrm{Ge}$ particles. The spherical ordered mesoporous carbon supplies channels able to alleviate the volume changes during the lithiation / delithiation cycling and ensures high electrical conductivity.

Decreasing the aggregation of Ge NPs occurring during electrodes' cycling represents another direction for improving the properties of Ge NPs based anodes for LIBs. NPs' anchoring on conductive substrates, such as graphene (Gr), CNTs, and RGO or NPs encapsulation in hollow carbon active material is accepted as the problem's solution. These carbon materials prevent large volumetric expansion thus ensuring long-term stability and high electrical conductivity resulting in high power of the batteries.

The reactive sites of nitrogen doped single walled carbon nanohorns (N-SWCNHs) were utilized by favourably growing of germanium nanocrystals (Ge $\mathrm{NCs}$ ) onto their conical tips by applying oleylamine as a reducing agent [14]. The prepared Ge@N-SWCNHs composite was studied as an active anode material for LIBs. For this purpose CR2032 coin cells were elaborated with $\mathrm{Li}$ chips as reference and counter electrode, the separator was dried glass fibers membrane and the working electrode was Ge@N-SWCNHs composite, casted on a copper foil. The slurry casted on the foil consisted of 70 wt.\%Ge@N-SWCNHs composite (containing 70 wt.\% Ge), 20\% Super-P carbon and 10\% PVDF in N-methyl-2-pyrrolidone (NMP). The electrolyte was $1 \mathrm{M} \mathrm{LiPF}_{6}$ dissolved in 1:1 mixture of EC and DMC with $5 \mathrm{v} . \%$ of $\mathrm{VC}$ as an additive.

The capacity of Ge@N-SWCNHs composite based electrode after 5 cycles stabilized at $1435 \mathrm{mAh} / \mathrm{g}$ while for an electrode based on Ge NCs as an active material the capacity was $1046 \mathrm{mAh} / \mathrm{g}$. The higher capacities obtained for Ge@N-SWCNHs composites were assigned to the lower activation energies permitting entire utilization of active material. The capacity retention of electrodes based on Ge NCs and Ge@NSWCNHs composites was tested for over 100 cycles. Pristine Ge NCs and Ge@N-SWCNHs composites showed stable discharge capacities of 811 and $1285 \mathrm{mAh} / \mathrm{g}$ after 100 cycles, correspondingly. The main part of the delithiation capacity in $\mathrm{Ge} @ \mathrm{~N}-\mathrm{SWCNHs}$ composite was lost during the initial 10 cycles $(6 \%)$ while the loss was $2.5 \%$ for the remaining 90 cycles. The CE of Ge@N-
SWCNHs composite after 20th cycle was higher than $95 \%$, and for the 80 th cycle it was practically $100 \%$.

The rate behaviour of Ge@SWCNHs composite was studied at various charge / discharge rates and compared with the behaviour of $\mathrm{Ge} \mathrm{NCs}$ and of pristine NSWCNHs under the same conditions. At rates of $0.1 \mathrm{C}$, $0.4 \mathrm{C}, 0.8 \mathrm{C}, 1 \mathrm{C}, 2 \mathrm{C}$ and $5 \mathrm{C}$ the capacity of $\mathrm{Ge} @ \mathrm{~N}-$ SWCNHs composite based electrodes was 1420, 1193, $935,866,611,366 \mathrm{mAh} / \mathrm{g}$, correspondingly. The capacity of Ge NCs based electrodes was 908, 762, 599, 462 , and $271 \mathrm{mAh} / \mathrm{g}$ at $0.1 \mathrm{C}, 0.4 \mathrm{C}, 1 \mathrm{C}, 2 \mathrm{C}$ and $5 \mathrm{C}$ correspondingly, while the capacity of pristine NSWCNHs was $48,36,26,15$ and $9 \mathrm{mAh} / \mathrm{g}$ at $0.2 \mathrm{C}$, $0.4 \mathrm{C}, 0.6 \mathrm{C}, 0.8 \mathrm{C}$ and $1 \mathrm{C}$ respectively. When after applying the highest discharge rate, it was returned to $0.1 \mathrm{C}$, the capacity of Ge NCs based electrode was 850 $\mathrm{mAh} / \mathrm{g}$, while the $\mathrm{Ge} @ \mathrm{SWCNHs}$ based electrode recovered its original capacity of $1413 \mathrm{mAh} / \mathrm{g}$.

The high storage capacities and the excellent rate behaviour of Ge@N-SWCNHs were assigned to the very good contact between Ge NCs and N-SWCNHs leading to high utilization of the active material. The preferential growth of Ge NCs on the tips of N-SWCNHs averts the NCs aggregation after many charge/discharge cycles.

Production of N-SWCNHs is relatively cheap and scalable and this makes the synthesized composite a promising candidate for LIBs anodes.

A layered germanium phosphide $\left(\mathrm{GeP}_{3}\right)$ - carbon black nanocomposite was prepared by high-power ballmilling technique [15]. The nanocomposite was tested as active material for LIBs anode. A button-type electrochemical half cell was assembled where Li metal was applied a as the counter and reference electrodes, the separator was Celgard 2400 membrane, and electrolyte was $1 \mathrm{M} \mathrm{LiPF}_{6}$ dissolved in EC - DEC (1:1 by volume), containing 5\% fluorethylene. The electrode exhibited a capacity of $1450 \mathrm{mAh} / \mathrm{g}$ after 30 cycles at rate of 100 $\mathrm{mA} / \mathrm{g}$. At high current $(1900 \mathrm{~mA} / \mathrm{g})$ the capacity was 860 $\mathrm{mAh} / \mathrm{g}$. The CE was in the range $87-93 \%$ after 100 cycles. The observed good electrochemical and cycling performances were assigned to the presence of very small $\mathrm{GeP}_{3}$ nanocrystallites $(3-5 \mathrm{~nm})$ in the amorphous $\mathrm{C}$ matrix and to the created short $\mathrm{Li}^{+}$ion diffusion paths.

Recently Ge coating for a 3D porous carbon on the surface of $\mathrm{Ni}$ foam has been prepared by ionic liquid electrodeposition followed by annealing [16]. Thus a 3DVoid/Ge@C composite has been produced. The material has been tested as a LIB anode. At current densities of $0.1,0.2,0.5,1$, and $2 \mathrm{~A} / \mathrm{g}$, the electrode has shown a reversible specific capacity of $1592.9,1054.9$, $921.3,771.4$, and $471.2 \mathrm{mAh} / \mathrm{g}$, correspondingly. The good performance of the prepared material has been ascribed to (a) the elasticity of the carbon sheet that facilitates the contact with Ge nanoparticles and protects pathways for the Li-ions transport and (b) the created 3D micro-nano void structure that decreases the damage from large volume changes during the intercalation and deintercalation process of $\mathrm{Li}^{+}$ions.

Three-dimensional nitrogen-doped graphene foam (NGF) has been prepared that contained interconnected pores and encapsulated Ge quantum dots. The obtained material was covered with polydimethylsiloxane to 
produce yolk-shell nanoarchitecture [17]. The material performance was tested by preparing two-electrode CR2025-type coin cells. The separator was porous polypropylene film, lithium foil was used as the counter electrode and $1 \mathrm{M}$ solution of $\mathrm{LiPF}_{6}$ in the mixture EC DMC - DEC (at volumetric ratio of $1: 1: 1$ ) was used as an electrolyte. Thus prepared nanocomposite (Ge-QD@, NG/NGF /PDMS) showed a reversible capacity of 1220 $\mathrm{mAh} / \mathrm{g}$ at current of $1600 \mathrm{~mA} / \mathrm{g}$, preserved for 1000 cycles. The material exhibited high rate capability of more than $800 \mathrm{mAh} / \mathrm{g}$ at current of $64 \mathrm{~A} / \mathrm{g}$ and 200 cycles. The averaged coulombic efficiency was $99.7 \%$ for the studied 1000 cycles. The excellent behavior of the prepared nanocomposite is assigned to the creation of internal void space that ensured better relieving the volume expansion during lithiation. In addition, the $\mathrm{N}$ doped graphene outer shell decreased significantly the exfoliation, pulverisation and aggregation of Ge. The elaborated material is suitable for preparing flexible electrodes.

In an attempt to overcome the negative effect of volume changes during the charging/discharging and the aggregation of $\mathrm{Ge}$ particles, a core-shell structured germanium@carbon (Ge@C) NPs were homogeneously anchored on the RGO nanosheets to obtain Ge@C/RGO hybrid [18]. Initially Ge NPs were prepared by a mechanochemical reaction between $\mathrm{GeO}_{2}$ and $\mathrm{Mg}$ powders. Further, Ge NPs were coated with polydopamine films, thus core-shell structured germanium@polydopamine (Ge@PDA) composite was prepared. The next step was the Ge@PDA anchoring on the graphite oxide (GO) making use of the dopamine strong adhesion, followed by calcination to form the Ge@C/RGO hybrids.

The electrochemical behavior of the prepared composite was studied using CR2025 coin-type cells in which working electrode consisted of active material (namely Ge@C/RGO, as well as Ge@C - for comparison), Super $\mathrm{P}$, and lithium polyacrylate at weight ratio of $8: 1: 1$, mixed with deionized water to form homogeneous slurry. Further, $\mathrm{Cu}$ foil, serving as a current collector, was coated with the slurry, cast in disks and dried. Li metal was used for counter and reference electrodes, and glass fiber for separator. The electrolyte was $1 \mathrm{M} \mathrm{LiPF}_{6}$ dissolved in $\mathrm{EC}-\mathrm{DMC}$ (1:1 by volume) with and addition of 5 wt.\% fluoride ethylene carbonate (FEC).

Initially charge and discharge specific capacities were 1692.3 and $1258.5 \mathrm{mAh} / \mathrm{g}$ at $\mathrm{C} / 10$ (the current density of $1 \mathrm{C}$ rate was $1600 \mathrm{~mA} / \mathrm{g}$ ), corresponding to an ICE of $74.4 \%$. This low ICE was assigned to decomposition of electrolyte and SEI formation. The initial discharge and charge capacity of the Ge@C, under the same conditions, were 1495.3 and $1252.1 \mathrm{mAh} / \mathrm{g}$, correspondingly. The higher ICE of the Ge@C compared to the Ge@C/RGO was explained by the higher specific surface area of the latter leading to more surface side reactions and thicker SEI layers. After the second cycle, the CE of Ge@C/RGO electrode reached over $98 \%$ and kept at that value for up to 600 cycles.

The reversible capacity of Ge@C/RGO electrode after 600 cycles at discharge rate of 2C was 1074.4
$\mathrm{mAh} / \mathrm{g}$, which is $96.5 \%$ of the capacity at the 2 nd cycle at $2 \mathrm{C}$. For comparison, the reversible capacity of the Ge@C electrode after 600 cycles at 2C was 362.6 $\mathrm{mAh} / \mathrm{g}$ indicating that only amorphous carbon layers cannot ensure stable long-term cycling performance.

Results from SEM and TEM analyses showed that after 600 discharging / charging cycles the Ge@C electrode suffers from significant pulverization and most of the active materials have lost contact with the current collector. Under the same conditions the Ge@C/RGO based electrode kept its surface morphology and structural stability. This is assigned to the high elasticity of RGO which was able to buffer the stress generated during the lithiation / delithiation of Ge.

The rate capability of $\mathrm{Ge} @ \mathrm{C} / \mathrm{RGO}$ and $\mathrm{Ge} @ \mathrm{C}$ electrodes was studied at different current densities. At the rates of $5 \mathrm{C}, 10 \mathrm{C}, 15 \mathrm{C}$, and $20 \mathrm{C}$ the $\mathrm{Ge} @ \mathrm{C} / \mathrm{RGO}$ electrode exhibited reversible capacities of 1319.0, 1104.1, 879.4, and $711.6 \mathrm{mAh} / \mathrm{g}$ respectively. Under the same current densities, the $\mathrm{Ge} @ \mathrm{C}$ electrode reversible capacities were 988.9, 511.0, 293.1 and $204.3 \mathrm{mAh} / \mathrm{g}$, respectively. When the rate was decreased to $0.2 \mathrm{C}$ the both electrodes recovered high capacity. After 200 cycles of lithiation/delithiation, no significant drop of capacity was observed at rates from $1 \mathrm{C}$ to $10 \mathrm{C}$. The specific capacity of $\mathrm{Ge} @ \mathrm{C} / \mathrm{RGO}$ electrode after 200 cycles decreased to $436 \mathrm{mAh} / \mathrm{g}$ at rate of $20 \mathrm{C}$. However, this is still higher than the theoretical capacity of graphite anode (372 mAh/g).

The excellent rate performance of the Ge@C/RGO electrode is assigned to the double carbon matrix composed of amorphous carbon and RGO nanosheets. The carbon layers ensure conductive pathways for diffusion of electrons and $\mathrm{Li}^{+}$. The homogeneous and continuous carbon layers in the core-shell structured Ge@C composite alleviate the large volume changes of Ge during lithiation / delithiation and improve the conductivity of Ge electrode. The uniform anchoring of the core-shell structured Ge@C particles onto the surface of RGO decreases the agglomeration of Ge@C composites and betters the active materials' utilization. The highly flexible RGO nanosheets decrease the stress resulting from the multiple volume changes and enhance the structural stability of electrode during cycling. In addition, Gr nanosheets and carbon shells create a hybrid conductive matrix, which improves the electronic conductivity and minimizes the volume change of Ge.

Similarly, a double-layered protective structure was synthesized in which the hollow cubic Ge@C hybrids were evenly dispersed on RGO sheets, thus forming Ge@C-RGO composite [19]. To prepare the composite Ge-bearing precursor $\left(\mathrm{NH}_{4} \mathrm{H}_{3} \mathrm{Ge}_{2} \mathrm{O}_{6}\right)$ was dopaminecoated and further subjected to carbothermal reduction processes to obtain a Ge@C composite where the carbon is N-doped. Further, the cubic Ge@C was dispersed on the RGO. The RGO along with the carbon layer formed a double carbon layer structure protecting Ge particles.

The electrochemical properties of the as-prepared material were studied using CR2032 coin-type cells. The Ge@C-RGO composite was applied as an active material. It was mixed with conductive carbon black and the binder (PVDF) at a mass ratio of 80:10:10, and 
dissolved in NMP to prepare a suspension, cast on a $\mathrm{Cu}$ foil (current collector). Thus prepared system was used as an anode, Li metal was the counter electrode and the electrolyte was $1.0 \mathrm{M}$ LiPF6 in EC - DEC $(1: 1$ by volume) and 5 wt.\% FEC. For comparative purposes, cells using Ge@C or Ge as active anode material were also prepared and studied.

It was found that the discharge capacities of $\mathrm{Ge} @ \mathrm{C}$ RGO, Ge@C and Ge electrodes at $100 \mathrm{~mA} / \mathrm{g}$ for 200 cycles were 1183, 567 and $202 \mathrm{mAh} / \mathrm{g}$, correspondingly. The reversible capacity of Ge@C-RGO based electrode at current of $1 \mathrm{~A} / \mathrm{g}$ for 200 cycles was $710 \mathrm{mAh} / \mathrm{g}$, and the $\mathrm{CE}$ reached $99.30 \%$.

The rate capability was studied at specific currents of $100,200,500$ and $1000 \mathrm{~mA} / \mathrm{g}$. The capacities delivered by Ge@C-RGO were 999, 796, 718, and $664 \mathrm{mAh} / \mathrm{g}$ correspondingly, while the Ge@C electrode exhibited capacities of 589, 540, 461 and $418 \mathrm{mAh} / \mathrm{g}$ under the same conditions. When the specific current returned back to $100 \mathrm{~mA} / \mathrm{g}$, the capacities were 991 and 576 $\mathrm{mAh} / \mathrm{g}$ for $\mathrm{Ge} @ \mathrm{C}-\mathrm{RGO}$ and $\mathrm{Ge} @ \mathrm{C}$ respectively, indicating good reversibility of the both electrodes. At the same time, the pure Ge electrode showed a continuous decline in capacity at each current rate, indicating its poor electrochemical stability.

The outstanding electrochemical performance of the $\mathrm{Ge} @ \mathrm{C}-\mathrm{RGO}$ based electrode is assigned to the formation of a double-carbon layer protective structure in which the hollow cubic Ge@C hybrids are evenly dispersed on the graphene sheets. The connected carbon shells, as a support structure, keep the shape of the material, alleviating the changes during the cycling, and the $\mathrm{Ge} @ \mathrm{C}$ core-shell structure ensures space for the volume expansion of Ge particles. RGO as a supporting substrate ensures good dispersion and fixation of Ge@C hybrids and with its large-area and high-flexibility buffers the stress caused by volume changes during charging / discharging. The N-doped carbon shell and the graphene network speed-up the transport of $\mathrm{Li}^{+}$. The dispersed small Ge nanoparticles shorten the $\mathrm{Li}^{+}$transport path. The both effects contribute to the improved overall conductivity of Ge@C-RGO electrode.

Chen and coauthors reported in situ synthesis of Ge/RGO composites using $\mathrm{GeO}_{2}$, as Ge source and $\mathrm{NaBH}_{4}$ as reductant. The process was assisted by a cationic polymer - poly(diallyldimethylammonium chloride [20]. In this synthesis $\mathrm{GeO}_{3}{ }^{2-}$ anions were adsorbed on cationic polymer-modified graphene oxide sheets by means of an electrostatic interaction. Further, in-situ reduction was carried out leading to the formation of ultrafine Ge nanoparticles (ca. $5 \mathrm{~nm}$ ) on RGO sheets thus creating uniform sandwich-like structure.

The prepared composite was studied as an active material for LIB, using two-electrode CR2032-type coin cells. Besides the prepared composite, the working electrodes contained conductive agent (acetylene black) and binder carboxymethyl cellulose sodium at weight ratio of $8: 1: 1$. The mixture was dispersed in deionized water and thus formed homogeneous slurry was uniformly coated onto pure $\mathrm{Cu}$ foil (serving as current collector), dried and cut into disks used as the working electrodes. Lithium foil was applied as both reference and counter electrodes. The electrolyte was $1.0 \mathrm{M} \mathrm{LiPF}_{6}$ dissolved in EC - DMC (1:1 by volume) containing 5 wt. \% FEC. A full Li-ion cell was also prepared with a cathode, based on commercial $\mathrm{LiFePO}_{4}$. The $\mathrm{LiFePO}_{4}$ electrode was made by mixing $80 \mathrm{wt} \%$ of $\mathrm{LiFePO}_{4}, 10$ $\mathrm{wt} \%$ of acetylene black and $10 \mathrm{wt} \%$ of PVDF in NMP. Further, the slurry was spread on an Al foil and dried. Before fabricating the full cell, the Ge/RGO anode was pre-lithiated by placing it in direct contact with a lithium foil in the presence of the cell electrolyte.

It was found that the amount of used RGO influences the electrochemical behavior of the Ge/RGO composite. For the composite with the optimal RGO content the initial charge and discharge specific capacities were 2100 and $1184 \mathrm{mAh} / \mathrm{g}$ respectively, resulting in an ICE of $56.4 \%$. The relatively low ICE was assigned to the formation of SEI films. The CE increased to ca. $95.0 \%$ at the $3 \mathrm{rd}$ cycle, and after 5 th cycle became above $99.0 \%$ and remained at that value after the 100 cycles at current density of $0.2 \mathrm{~A} / \mathrm{g}$.

After 100 cycles the Ge/RGO-based electrode exhibited discharge capacity of approximately 960 $\mathrm{mAh} / \mathrm{g}$ at $0.2 \mathrm{~A} / \mathrm{g}$, while the specific capacity of the prepared for comparative purposes pristine Ge-based electrode was $503 \mathrm{mAh} / \mathrm{g}$ after 100 cycles. The improved specific capacity of Ge/RGO-based electrode was explained with the high electrical conductivity and large specific surface area of the RGO matrix.

The rate performance was studied at different current densities. The specific capacities of $\mathrm{Ge} / \mathrm{RGO}$ based electrode at $0.1,0.2,0.4,0.8,1,2$ and $5 \mathrm{~A} / \mathrm{g}$ were 1290 , 1194, 1112, 1036, 985, 877 and $631 \mathrm{mAh} / \mathrm{g}$, correspondingly, while (for comparison) the specific capacity of pure Ge was $141 \mathrm{mAh} / \mathrm{g}$ at $5 \mathrm{~A} / \mathrm{g}$. When the current density of $\mathrm{Ge} / \mathrm{RGO}$ based electrode was returned back to $0.2 \mathrm{~A} / \mathrm{g}$, the reversible capacity recovered to $1177 \mathrm{mAh} / \mathrm{g}$.

The long-term cycling behavior of the Ge/RGO based electrode with the optimal RGO content was assessed at a current density of $1 \mathrm{~A} / \mathrm{g}$. The initial discharge capacity was $940 \mathrm{mAh} / \mathrm{g}$, and it was 705 $\mathrm{mAh} / \mathrm{g}$ after 350 cycles. Even at a high discharge rate of $5 \mathrm{~A} / \mathrm{g}$ the reversible capacity of the Ge/RGO based electrode was $480 \mathrm{mAh} / \mathrm{g}$ after 250 cycles.

Furthermore, the coin-type full cell with the Ge/RGO composite as anode and commercial $\mathrm{LiFePO}_{4}$ as cathode (at $85 \mathrm{~mA} / \mathrm{g}$ ) delivered an initial charge capacity of 149 $\mathrm{mAh} / \mathrm{g}$ and discharge capacity of $131 \mathrm{mAh} / \mathrm{g}$, which corresponds to the ICE of $87.9 \%$.

The full cell still possessed a good cycling stability with a specific capacity of $120 \mathrm{mAh} / \mathrm{g}$ after 100 cycles at $0.5 \mathrm{C}$. The $\mathrm{Ge} / \mathrm{RGO} / / \mathrm{LiFePO}_{4}$ full cell showed reversible capacities of $156,152,134,115,95,62,41$ and 16 $\mathrm{mAh} / \mathrm{g}$ at $0.1 \mathrm{C}, 0.2 \mathrm{C}, 0.5 \mathrm{C}, 1 \mathrm{C}, 2 \mathrm{C}, 5 \mathrm{C}, 10 \mathrm{C}$ and $15 \mathrm{C}$, correspondingly. When, after the high current discharge, the rate was returned back to $0.2 \mathrm{C}$, the capacity measured was $151 \mathrm{mAh} / \mathrm{g}$. These findings point at the applicability of the Ge/RGO composite as anode in commercial LIBs.

The outstanding electrochemical performance of Ge/RGO composite is assigned to the elaborated nanostructure and to the resulting synergistic effect 
between Ge NPs and RGO sheets. The two-dimensional structure and large surface area of the RGO facilitates the uniform dispersion of Ge NPs in RGO matrix, prevents their agglomeration and ensures more active sites for lithium storage. The Ge/RGO composite supplies enough void space to buffer the volume change of $\mathrm{Ge}$ and maintain high structural stability during cycling. RGO (when in optimal concentrations) with its high electrical conductivity promotes the electron transport. Its large area ensures better contact with the electrolyte and shortens the transport distance of $\mathrm{Li}^{+}$ions thus contributing to the superior rate capability.

Very recently germanene-reduced graphene oxide $\mathrm{GeCH}_{3} / \mathrm{RGO}$ nanocomposites have been synthesized and studies as anode materials for LIBs by using home-made 2032 cells [21]. The counter electrode was lithium metal, the separator - Celgard 3500 membrane and the electrolyte - $1 \mathrm{M} \mathrm{LiPF}_{6}$ dissolved in an EC - DEC DMC mixture (at 1: 1: 1 in volume) with $2 \%$ FEC. The results revealed that the reversible capacity of the material prepared with $30 \mathrm{wt} \%$ RGO content (the optimum composition) used as anode was $1195 \mathrm{mAh} / \mathrm{g}$ after 5 cycles, and even after 100 cycles it was 1058 $\mathrm{mAh} / \mathrm{g}$ showing a stable work. The CE was $98 \%$. Even after 500 cycles, the capacities of the material with optimal composition were 439 and $288 \mathrm{mAh} / \mathrm{g}$ at current densities of $0.5 \mathrm{~A} / \mathrm{g}$ and $1 \mathrm{~A} / \mathrm{g}$ correspondingly, and the respective $\mathrm{CE}$ were $98.58 \%$ and $99.31 \%$.

Only several months ago a material based on mixed Ge oxide and RGO has been presented [22]. The $\mathrm{CuGeO}_{3} / \mathrm{RGO}$ nanocomposite makes use of high capacity possessed by $\mathrm{CuGeO}_{3}$ and stable framework created by the RGO. Thus prepared composite was tested as anode active material for LIBs electrodes. The electrode was made of $80 \mathrm{wt} \% \mathrm{CuGeO}_{3} / \mathrm{RGO}, 10 \mathrm{wt} \%$ conductive acetylene black and $10 \mathrm{wt} \%$ binder (PVDF). CR2032-type coin half cells were prepared. The counter electrode was metallic $\mathrm{Li}$ and the electrolyte consisted of $\mathrm{LiPF}_{6}$ dissolved in EC - DEC (at ratio 1:1) with addition of $5 \mathrm{vol} \%$ of FEC. It has been found that composite $\mathrm{CuGeO}_{3} / \mathrm{RGO}$ containing $30 \mathrm{wt} \%$ GO exhibits very good electrochemical performance. It possessed a reversible capacity of $909 \mathrm{mAh} / \mathrm{g}$ and high $\mathrm{CE}$ of $91.49 \%$ at the current density of $100 \mathrm{~mA} / \mathrm{g}$ after 200 cycles. The specific capacities of the prepared composite were $709.4 \mathrm{mAh} / \mathrm{g}, 609.7 \mathrm{mAh} / \mathrm{g}$ and $523.4 \mathrm{mAh} / \mathrm{g}$ when it was cycled successively at $200 \mathrm{~mA} / \mathrm{g}, 500 \mathrm{~mA} / \mathrm{g}$ and $1000 \mathrm{~mA} / \mathrm{g}$. At restoration of the current density to 100 $\mathrm{mA} / \mathrm{g}$, the capacity recovered to $747.6 \mathrm{mAh} / \mathrm{g}$. The good electrochemical characteristics of the $\mathrm{CuGeO}_{3} / \mathrm{RGO}$ composite were assigned to the combined effect of the crystalline $\mathrm{CuGeO}_{3}$ nanorods and $\mathrm{RGO}$ sheets framework. The $\mathrm{CuGeO}_{3}$ nanorods ensure direct transport tunnels for lithium ions, while the RGO sheets supply a stable conductive network having large specific surface area for even dispersion of the $\mathrm{CuGeO}_{3}$. In addition, the RGO skeleton restricts the excess volume expansion of $\mathrm{CuGeO}_{3}$, thus preventing the pulverization of the electrode during the lithiation/delithiation process.

A brief summary of the studies carried out in the recent 3-4 years on Ge-based nanomaterials preparation and testing as anode materials for LIBs is presented in Table 1.

Table 1. Brief summary of the recent 3-4 years studies on Gebased nanomaterials for LIBs anodes.

\begin{tabular}{|c|c|c|c|c|}
\hline Material & $\begin{array}{c}\text { Capacity, } \\
\mathbf{m A h} / \mathrm{g}\end{array}$ & $\begin{array}{c}\text { Current } \\
\text { density, } \\
\text { mA/g }\end{array}$ & \begin{tabular}{|c|} 
Charge- \\
discharge \\
cycles \\
demonstrated
\end{tabular} & Ref. \\
\hline Ge NWs & 884 & 320 & 50 & 5 \\
\hline Ge/3DOM-Ni & 610 & 320 & 100 & 6 \\
\hline Porous Ge & $\begin{array}{c}649 \\
(1300)\end{array}$ & $\begin{array}{c}8000 \\
(1000)\end{array}$ & $1800(340)$ & 7 \\
\hline $\begin{array}{l}\mathrm{Ge} @ \mathrm{TiO}_{2} \\
\text { composite }\end{array}$ & 963 (717) & $\begin{array}{c}400 \\
(3200)\end{array}$ & $100(300)$ & 8 \\
\hline $\mathrm{GeO}_{2} \mathrm{NPs}$ & 582 & 100 & 100 & 9 \\
\hline $\mathrm{GeO}_{\mathrm{x}}-\mathrm{C}$ composite & $930(757)$ & $\begin{array}{c}630 \\
(4200)\end{array}$ & $100(400)$ & 10 \\
\hline $\begin{array}{c}\text { Ge NW/ Cu NW } \\
\text { composite }\end{array}$ & 889 & 1300 & 50 & 11 \\
\hline $\begin{array}{c}\text { Co-Ge core-shell } \\
\text { NW array } \\
\end{array}$ & $\begin{array}{c}1535 \\
(1239) \\
\end{array}$ & $\begin{array}{c}320 \\
(8000)\end{array}$ & $100(45)$ & 12 \\
\hline $\mathrm{S}-\mathrm{OMC} / \mathrm{Ge}$ & $996(530)$ & $\begin{array}{c}100 \\
(1000)\end{array}$ & $160(200)$ & 13 \\
\hline $\begin{array}{c}\text { Ge@N- } \\
\text { SWCNHscomposite }\end{array}$ & $\begin{array}{l}1285 \\
(866) \\
\end{array}$ & $\begin{array}{c}160 \\
(1600) \\
\end{array}$ & 100 & 14 \\
\hline $\begin{array}{c}\mathrm{GeP}_{3}-\mathrm{C} \text { black } \\
\text { composite }\end{array}$ & $\begin{array}{c}860 \\
(1450)\end{array}$ & $\begin{array}{l}1900 \\
(100) \\
\end{array}$ & $100(30)$ & 15 \\
\hline 3DVoid/Ge@C & $\begin{array}{c}990 \\
(1300)\end{array}$ & $\begin{array}{c}100 \\
(100)\end{array}$ & $100(10)$ & 16 \\
\hline $\begin{array}{c}\text { Ge-QD@ } \\
\text { NG/NGF/PDMS }\end{array}$ & $\begin{array}{l}1220 \\
(800) \\
\end{array}$ & $\begin{array}{c}1600 \\
(64000) \\
\end{array}$ & $1000(200)$ & 17 \\
\hline $\begin{array}{c}\mathrm{Ge} @ \mathrm{C} / \mathrm{RGO} \\
\text { hybrid }\end{array}$ & 1074.4 & 3200 & 600 & 18 \\
\hline Ge@C-RGO hybrid & $\begin{array}{l}1183 \\
(710) \\
\end{array}$ & $\begin{array}{c}100 \\
(1000)\end{array}$ & $200(200)$ & 19 \\
\hline Ge/RGO composite & $\begin{array}{l}960(705 \\
\text { and } 631)\end{array}$ & $\begin{array}{c}200 \\
(1000 \\
\text { and } \\
5000)\end{array}$ & $100(350)$ & 20 \\
\hline $\begin{array}{c}\mathrm{GeCH}_{3} / \mathrm{RGO} \\
\text { composite }\end{array}$ & $\begin{array}{l}1058 \\
(439) \\
\end{array}$ & $\begin{array}{c}200 \\
(500)\end{array}$ & $100(500)$ & 21 \\
\hline $\begin{array}{c}\mathrm{CuGeO}_{3} / \mathrm{RGO} \\
\text { composite }\end{array}$ & $\begin{array}{r}909 \\
(523) \\
\end{array}$ & $\begin{array}{c}100 \\
(1000) \\
\end{array}$ & $200(40)$ & 22 \\
\hline
\end{tabular}

\section{Conclusions and outlook}

As a conclusion it can be said that Ge NPs, Ge nanoalloys and Ge-based nanocomposites have been and are being widely studied for their ability to serve as advanced anodes in LIBs. These materials allow overcoming the problems related to volume expansion / contraction during the lithiation / delithiation reaction, while ensuring high reversible capacity and high rate under the applied test conditions.

However, studies on the cycling performance of the electrodes, based on the developed materials, seldom reach the cycles of the commercially used batteries. Further investigations in this direction are needed, with higher number of charge / discharge cycles.

Most of the cells assembled with the developed anodes resemble primary cells, the studies using as counter-electrode materials applied in real LIBs are very scarce. Studies of whole cells where the developed 
materials are working with cathodes based on commercially used materials are highly needed.

Efforts must be continued to find the conditions for convenient production of large quantities of nanomaterials for the preparation and testing of larger batteries, rather than individual electrochemical cells.

Finally, we can say that Ga-based nanomaterials are promising active matter for advanced anodes for LIBs but still much work is required for their implementation in the commercial batteries.

In addition, since the sodium ions cannot intercalate into graphite in a reversible manner, the Ge-based nanomaterials deserve more attention as eventual anodes for sodium-ion battery.

\section{References}

1. X. Li, J. Liang, Z. Hou, W. Zhang, Y. Wang, Y. Zhu, Y. Qian, The design of a high-energy Li-ion battery using germanium-based anode and $\mathrm{LiCoO}_{2}$ cathode. J. Power Sources 293, 868-875 (2015). doi:10.1016/j.jpowsour.2015.06.031

2. R.D. Deshpande, J.Li, Y.T. Cheng, M.W. Verbrugge, Liquid metal alloys as self-healing negative electrodes for lithium ion batteries. J. Electrochem. Soc. 158, A845-A849 (2011). doi:10.1149/ 1.3591094

3. Z. Hu, S. Zhang, C. Zhang, G. Cui, High performance germanium-based anode materials. Coordin Chem Rev 326, 34-85 (2016). doi:10.1016/j.ccr. 2016.08.002

4. D. Carolan, Recent advances in germanium nanocrystals: Synthesis, optical properties and applications. Prog. Mater. Sci. 90, 128-158 (2017). doi:10.1016/j.pmatsci.2017.07.005

5. Z. Yu, X. Meng, M. Yin, M. Sun, M. Yuan, H. Li, Pulsed laser-assisted ionic liquid electrodeposition of gallium nanoparticles and germanium nanostructures for energy storage. Chem. Phys. Lett. 698, 181-186 (2018). doi:10.1016/j.cplett.2018.03.023

6. X. Liu, Y. S. Liu, M.M. Harris, J.Li, K.X. Wang, J.S. Chen, Germanium nanoparticles supported by 3D ordered macroporous nickel frameworks as highperformance free-standing anodes for Li-ion batteries. Chem. Eng. J. 354, 616-622 (2018). doi:10.1016/j.cej.2018.08.056

7. K. Mishra, X.C. Liu, F.S. Ke, X.D. Zhou, Porous germanium enabled high areal capacity anode for lithium-ion batteries. Composites Part B 163, 158164 (2019). doi:10.1016/j.compositesb.2018.10.076

8. Q. Liu, J. Hou, C. Xu, Z. Chen, R. Qin, H. Liu, $\mathrm{TiO}_{2}$ particles wrapped onto macroporous germanium skeleton as high performance anode for lithium-ion batteries. Chem. Eng. J. 381, 122649 (2020). doi:10.1016/j.cej.2019.122649

9. J. Zhang, T. Yu, J. Chen, H. Liu, D. Su, Z. Tang, J. Xie, L. Chen, A. Yuan, Q. Kong, Germanium-based complex derived porous $\mathrm{GeO}_{2}$ nanoparticles for building high performance Li-ion batteries. Ceram. Int. 44, 1127-1233 (2018). doi:10.1016/j.ceramint. 2017.10.069

10. S.Y. Lim, W. Jang, S. Yun, W.S. Yoon, J.Y. Choi, D. Whang, Amorphous germanium oxide nanobubbles for lithium-ion battery anode. Mater. Res. Bull. 110, 24-31 (2019). doi:10.1016/j.materresbull.2018.10.007

11. K.T. Chen, W.C. Chang, H.J. Yang, C.Y. Tsai, S.B. Huang, H.Y. Tuan, Free standing $\mathrm{Si}$ (Ge) nanowire $/ \mathrm{Cu}$ nanowire composites as lithium ion battery anodes. J. Taiwan Inst. Chem. E 104, 54-64 (2019). doi:10.1016/j.jtice.2019.07.014

12. W. Zhao, J. Chen, Y. Lei, N. Du, D. Yang, A novel three-dimensional architecture of $\mathrm{Co}-\mathrm{Ge}$ nanowires towards high-rate lithium and sodium storage. J. Alloy. $\quad$ Compd. $815 \quad$ (2020). doi:10.1016/j.jallcom.2019.152281

13. M. Zhao, D.L. Zhao, X.Y. Han, H.X. Yang, Y.J. Duan, X.M. Tian, Ge nanoparticles embedded in spherical ordered mesoporous carbon as anode material for high performance lithium ion batteries. Electrochim. Acta 287, 21-28 (2018). doi:10.1016/j.electacta.2018.08.050

14. U. Gulzar, T. Li, X. Bai, S. Goriparti, R. Brescia, C. Capiglia, R.P. Zaccaria, Nitrogen-doped single walled carbon nanohorns enabling effective utilization of $\mathrm{Ge}$ nanocrystals for next generation lithium ion batteries. Electrochim. Acta 298, 89-96 (2019). doi:10.1016/j.electacta.2018.11.130

15. K.H. Nam, K.J. Jeon, C.M. Park, Layered germanium phosphide-based anodes for highperformance lithium- and sodium-ion batteries. Energy Storage Mater. 17, 78-87 (2019). doi:10.1016/j.ensm.2018.07.026

16. X. Liu, T. Ji, T. Nie, T. Wang, Z. Liu, S. Liu, J. Zhao, Y. Li, A nano-Ge-coated 3D porous carbon fabricated by ionic liquid electrodeposition for application in lithium storage. Mater. Lett. 261 (2020). doi:10.1016/j.matlet.2019.127157

17. R. Mo, D. Rooney, K. Sun, H.Y. Yang, 3D nitrogendoped graphene foam with encapsulated germanium/nitrogen-doped, graphene yolk-shell nanoarchitecture for high-performance flexible Liion battery. Nat. Commun. 8 (2017). doi:10.1038/ncomms13949

18. B. Wang, Z. Wen, J. Jin, X. Hong, S. Zhang, K. Rui, A novel strategy to prepare $\mathrm{Ge} @ \mathrm{C} / \mathrm{RGO}$ hybrids as high-rate anode materials for lithium ion batteries. J. Power Sources 342, 521-528 (2017). doi:10.1016/j.jpowsour.2016.12.091

19. M. Zhao, D.L. Zhao, H.X. Yang, X.Y. Han, Y.J. Duan, X.M. Tian, W.J. Meng, Graphene-supported cubic hollow carbon shell-coated germanium particles as high-performance anode for lithium-ion batteries. Ceram. Int. 45, 13210-13218 (2019). doi:10.1016/j.ceramint.2019.04.005

20. Y. Chen, L. Ma, X. Shen, Z. Ji, A. Yuan, K. Xu, S. A. Shah, In-situ synthesis of Ge/reduced graphene 
oxide composites as ultrahigh rate anode for lithium-ion battery. J. Alloy. Compd. 801, 90-98 (2019). doi:10.1016/j.jallcom.2019.06.074

21. F. Zhao, Y. Wang, X. Zhang, X. Liang, F. Zhang, L. Wang, Y. Li, Y. Feng, W. Feng, Few-layer methylterminated germanene-graphene nanocomposite with high capacity for stable lithium storage. Carbon 161, 287-298 (2020). doi:10.1016/j.carbon.2020.01.072

22. W.J. Meng, M. Zhao, H.X. Yang, Y.Q. Wu, H. Pu, R.Z. Gao, Y. Yang, D.L. Zhao, Synthesis of $\mathrm{CuGeO}_{3} /$ reduced graphene oxide nanocomposite by hydrothermal reduction for high performance Li-ion battery anodes. Ceram. Int. 46(7), 9249-9255 (2019). doi:10.1016/j.ceramint.2019.12.178 